\title{
Comparison of Resonance Characteristics between Children with Cochlear Implants and Children with Normal Hearing
}

\author{
Mun-Chul Chae ${ }^{1,2}$, Chul-Hee Choi ${ }^{2,3}$, Seong Hee Choi ${ }^{2,3}$ \\ ${ }^{1}$ Aisarang Children Development Center, Daegu, Korea \\ ${ }^{2}$ Department of Audiology and Speech-Language Pathology, The Graduate School of Health and Medical Science, Daegu Catholic University, \\ Gyeongsan, Korea \\ ${ }^{3}$ Department of Audiology and Speech-Language Pathology, Research Institute of Biomimetic Sensory Control, \\ Catholic Hearing Voice Speech Center, Daegu Catholic University, Gyeongsan, Korea
}

\section{인공와우 이식 아동과 건청 아동의 공명 특성 비교}

채문철 $^{1,2} \cdot$ 최철희 ${ }^{2,3} \cdot$ 최성희 ${ }^{2,3}$

아이사랑아동발달센터 ${ }^{1}$, 대구가톨릭대학교 의료보건과학대학원 언어청각치료학과 ${ }^{2}$, 대구가톨릭대학교 바이오메디대학 언어청각치료학과, 생체모방감각제어연구소, 가톨릭 청각음성언어센터 ${ }^{3}$

\begin{abstract}
Purpose: The present study examined the nasalance (\%) and resonance characteristics in children with normal hearing (NH) and children with cochlear implants (CI) using Nasometer II 6564 (KAY Elemetrics Corp.). Methods: Twenty NH and twenty Cl participated in this study. Of twenty children with $\mathrm{Cl}$, ten (Cl-B) had the $\mathrm{Cl}$ surgery before three years old and the other ten had after three years old (Cl-A). Results: For nasalance of vowels, significantly higher nasalance scores in $\mathrm{Cl}$ than $\mathrm{NH}$ and vowel /i/ was significantly higher than vowel /u/ and / a/. However, no significant differences were found in $\mathrm{Cl}-\mathrm{B}$ and $\mathrm{Cl}-\mathrm{A}$. Likewise, for oral-sound sentences, significantly higher nasalance scores were observed in $\mathrm{Cl}$ than $\mathrm{NH}$ whereas no difference between $\mathrm{Cl}-\mathrm{B}$ and $\mathrm{Cl}-\mathrm{A}$. For nasal and nasal-sound sentences, there were no significant differences between $\mathrm{NH}$ and $\mathrm{Cl}$, and between $\mathrm{Cl}-\mathrm{B}$ and $\mathrm{Cl}-\mathrm{A}$ although lower nasalance scores were found in $\mathrm{Cl}$. Generally, $\mathrm{Cl}$ showed seldom normal resonance (10\%) and most of $\mathrm{Cl}$ demonstrate deviant resonance patterns (90\%). Hypernasality was typical resonance pattern, followed by hyponasality, mixed nasality, and cul-de-sac resonance regardless of age of implantation in $\mathrm{Cl}$. Conclusion: Although hearing improves following $\mathrm{Cl}$, most children with $\mathrm{Cl}$ demonstrated still abnormal resonance patterns in comparison with $\mathrm{NH}$, which may affect normal speech production. In addition, normal resonance was seldom observed regardless of $\mathrm{Cl}$ surgery period. Therefore, auditory rehabilitation for resonance was needed after $\mathrm{Cl}$ for normal speech production.
\end{abstract}

Key Words: Cochlear implants, Resonance disorders, Nasalance, Auditory-perceptual judgement.

Received: October 2, 2017 / Revised: October 17, 2017 / Accepted: October 18, 2017

Correspondence: Seong Hee Choi, Department of Audiology and Speech-Language Pathology, Research Institute of Biomimetic Sensory Control, and Catholic Hearing Voice Speech Center, Daegu Catholic University, 13-13 Hayang-ro, Hayang-eup, Gyeongsan 38430, Korea

Tel: +82-53-850-2542 / Fax: +82-53-359-0780 / E-mail: shgrace@cu.ac.kr

\section{INTRODUCTION}

선천적 또는 후천적으로 청력손실을 가진 청각 장애인들은 소리를 충분히 듣지 못하게 되고 이로 인하여 타인과의 의사소 통에 문제가 발생한다. 이러한 의사소통의 문제는 심리사회적 어려움의 원인이 될 수 있다. 대부분의 난청은 보청기로 도움을 받을 수 있으나, 보청기는 고심도 이상의 청력손실을 가진 청각
장애인에게는 제한된 청각적 보상을 주기 때문에 다양한 주파 수들로 결합된 복합음인 음성언어를 듣는 데 한계가 있다. 따라 서 보청기로 충분한 도움을 받을 수 없는 경우, 인공와우 이식 (cochlear implants, CI)을 고려할 수 있다. 국내에서는 2005년 부터 인공와우 기술의 발전과 건강보험 급여 적용의 확대로 비 용이 절감되어 이식의 기회가 늘어나고 있으며, 학령기 청각 장 애 아동의 통합 교육과 CI 성인의 사회적 통합이 점차 확대되고 
있는 실정이다.

선행연구에 의하면, 청각 장애인은 말 산출 기관의 기질적인 문제가 없음에도 불구하고 건청인과는 다른 말 산출의 특성을 보인다. 첫째, 청각 장애인은 말 산출 시에 흡기와 호기류를 조절 하는 데 어려움을 보인다. 즉, 발화시 건청인에 비해 쉼의 길이가 길고, 흡기류를 사용하는 등 발성 동안 부적절한 호흡 패턴이 관 찰된다고 하였다(Yoon, 2004). 둘째, 청력손실 정도가 심할수록 음도, 강도의 문제와 관련된 음성 문제가 나타날 수 있으며 청각 장애 아동들은 연령이나 성별에 적합하지 않은 높은 음도나 낮은 음도를 사용하기도 한다(McGarr \& Osberger, 1978). 셋째, 고심 도 난청이나 농을 가진 청각 장애인은 청각적 피드백이 부족하 여 공명의 문제를 보이기도 한다. 특히, 적절한 음성 훈련을 받 지 못한 청각 장애인에게 두드러지게 나타나는데 이러한 공명의 문제는 지나친 인두공명으로 인한 맹관공명을 수반하거나, 혀 위치를 지나치게 하인두 쪽으로 위치시키는 것이다. 또한 구강 과 비강을 분리하여 말 산출 조절을 하지 못해 비강에 너무 중 점을 두어 발성하는 과다비성(hypernasality)을 보이거나, 이와 는 반대로 비강공명이 충분하지 못한 과소비성의 형태를 보이기 도 한다. 또한 청각 장애인들은 낮은 비음치를 보이거나(Fletcher et al., 1999), 혹은 높은 비음치를 나타내기도 한다(Fletcher \& Daly, 1976; Nguyen et al., 2008). 넷째, 선천성 청각 장애 아 동들은 청각적 피드백의 부족으로 인해 조음 산출 시 왜곡이나 대치와 같은 조음 오류의 형태를 보이기도 한다. 이러한 선천성 청각 장애 아동의 음운적 특징으로는 자음의 생략과 대치, 왜 곡, 모음의 중모음화와 같은 특징을 나타낸다(Sehr et al., 2002). 현재까지 국내에서 CI 아동을 대상으로 한 연구로는 CI 아동과 건청 아동 음성의 음향학적 특성(Choi et al., 2010; Jun \& Ko, 2007; Kim \& Ko, 2007; Yoon et al., 2013)에 대한 연구가 대부 분이었으며, 최근 성인을 대상으로 한 연구가 이루어졌으나 (Kim, 2009), CI 아동의 공명 특성에 대한 연구는 매우 부족하 다. 따라서 본 연구에서는 $\mathrm{CI}$ 아동과 건청인 아동의 다양한 말 문맥에서 비음치를 측정하여 $\mathrm{CI}$ 아동과 건청인 아동의 공명적 특성을 알아보고, $\mathrm{CI}$ 아동의 이식 시기에 따른 공명적 특성을 비음치와 청지각적 평가를 통하여 알아보고자 한다.

\section{MATERIALS AND METHODS}

\section{연구 대상}

\section{$\mathrm{Cl}$ 아동}

연구 시작 전 부모에게 연구 목적에 대해 설명 후 사전 동의 를 받아 가능한 경우만 연구 대상으로 참여하였다. CI 아동은 대 구과 부산에 거주하는 아동 20명을 대상으로 하였다(Table 1).
$\mathrm{CI}$ 집단의 선정기준은 다음과 같다. 1) 생활연령이 5 9세 아동, 2) 선천성 청각 장애 아동, 3) CI를 받은 지 1년 이상인 아동, 4) 부모와 교사에 의해 인지가 정상으로 보고되는 아동, 5) 중복 장 애를 동반하지 않는 아동, 6) 이식 후 주 의사소통 수단이 구어 인 아동, 7) 모음과 자음 발성이 가능하고 문장 수준의 발화가 가능한 아동을 대상으로 하였다. 위의 기준에 해당하는 아동 20 명을 CI 시기에 따라 3세 이전에 인공와우를 이식한 아동 10 명, 3 세 이후에 인공와우를 이식한 아동 10 명으로 구분하였다. CI 후 와우 착용 기간을 1 년 이상 착용 아동 대상으로 한 것은 와 우 이식 후 1년 뒤에 와우 이식에 대한 효과를 볼 수 있다는 선 행연구에 의해 1년 이상으로 제안하였다(Mondain et al., 1997). 또한 대상자의 연령을 9세로 제한한 것은 공명 평가 시 대상자 의 변성에 의한 공명 평가의 영향이 미치지 않도록 하기 위하여 Oh et al.(2000) 선행연구에 따라 9세 이하의 아동을 선정 대상 으로 하였다. 그리고 주 의사소통 수단을 구화 사용자로 제안한 것은 Jung(2002)의 선행연구에서 수화를 사용하는 아동이 구 화를 사용하는 아동보다 말소리의 이해가 낮고 음성 사용이 제 한적이기 때문이다. 본 연구의 CI 아동 20 명 모두 인공와우 착 용 후의 교정 청력이 20 30 dB HL 수준이었고, 양이 인공와우 는 없었으며 인공와우 반대쪽에 보청기를 착용한 아동은 남아 2 명, 여아 1 명이었다.

\section{건청 아동}

건청 아동은 대구 지역에 거주하는 아동 20명을 대상으로 하 였다(Table 1). 건청 아동 선정기준은 다음과 같다. 1) CI 아동 과 성별이 일치하고 연령이 \pm 6개월 이내에 있는 아동, 2) 부모 또는 교사로부터 대상 아동이 청각 장애나 인지 장애가 없고 말 산출 기관의 기질적, 기능적 문제가 없으며, 행동에 대한 문 제가 없다고 보고된 아동을 대상으로 하였다.

\section{연구 절차}

\section{검사어 수집}

검사어는 모음 연장 발성과 문단 읽기의 두 종류를 실시하였 다(Appendix). 모음 연장 발성은 /아, 이, 우/ 세 가지 모음을 사용하였으며, 문단의 경우 구강음 문단, 비음 문단, 구강음-비 음 문단을 사용하였다.

모음과 비음이 제외된 구강음 문단에서 과다비성을 확인하였 으며, 구강음이 제외된 비음 문단에서 과소비성을 평정하였다. $\operatorname{Kim}(2009)$ 의 연구에서와 같이 비정상 비음치군의 분류는 문단 과제에서의 〈Appendix〉에 제시된 기준치의 \pm 2 standard deviation를 벗어나는 경우, 비정상 비음치로 간주하였다(Table 2). 
Table 1. Demographic information of the partcipants

\begin{tabular}{|c|c|c|c|c|c|c|c|}
\hline \multicolumn{6}{|c|}{$\mathrm{CI}$} & \multicolumn{2}{|r|}{$\mathrm{NH}$} \\
\hline CI groups & Gender & Age (year;month) & CI time (year;month) & CI ear & Hearing threshold & Gender & Age (year;month) \\
\hline \multicolumn{8}{|l|}{ CI-A } \\
\hline 1 & M & $6 ; 5$ & $2 ; 00$ & Rt & Deaf & M & $6 ; 3$ \\
\hline 2 & M & $5 ; 8$ & $2 ; 00$ & Rt & Deaf & M & $5 ; 5$ \\
\hline 3 & M & $5 ; 7$ & $2 ; 00$ & $\mathrm{Lt}$ & Lt 90 dB, Rt $100 \mathrm{~dB}$ & M & $5 ; 3$ \\
\hline 4 & M & $6 ; 4$ & $2 ; 00$ & Rt & Lt 100 dB, Rt $100 \mathrm{~dB}$ & M & $6 ; 2$ \\
\hline 5 & M & $7 ; 4$ & $2 ; 6$ & Rt & Lt 90 dB, Rt 90 dB & M & $7 ; 6$ \\
\hline 6 & $\mathrm{~F}$ & $7 ; 4$ & $1 ; 6$ & Lt & Lt $85 \mathrm{~dB}$, Rt $90 \mathrm{~dB}$ & $\mathrm{~F}$ & $7 ; 10$ \\
\hline 7 & M & $7 ; 2$ & $2 ; 0$ & Rt & Lt $110 \mathrm{~dB}$, Rt $110 \mathrm{~dB}$ & M & $7 ; 5$ \\
\hline 8 & M & $5 ; 8$ & $2 ; 0$ & $\mathrm{Lt}$ & Lt 90 dB, Rt 100 dB & M & $5 ; 7$ \\
\hline 9 & M & $5 ; 9$ & $2 ; 0$ & Rt & Lt 100 dB, Rt 105 dB & M & $5 ; 10$ \\
\hline 10 & $\mathrm{~F}$ & $5 ; 7$ & $1 ; 8$ & Rt & Lt 90 dB, Rt 90 dB & $\mathrm{F}$ & $5 ; 9$ \\
\hline \multicolumn{8}{|l|}{ CI-B } \\
\hline 11 & M & $5 ; 0$ & $3 ; 4$ & Rt & Lt 100 dB, Rt $90 \mathrm{~dB}$ & M & $5 ; 3$ \\
\hline 12 & M & $6 ; 0$ & $3 ; 0$ & Lt & Lt $80 \mathrm{~dB}$, Rt $90 \mathrm{~dB}$ & M & $6 ; 2$ \\
\hline 13 & M & $6 ; 3$ & $3 ; 3$ & Rt & Lt 105 dB, Rt $100 \mathrm{~dB}$ & M & $7 ; 5$ \\
\hline 14 & F & $7 ; 3$ & $3 ; 11$ & $\mathrm{Lt}$ & Lt $110 \mathrm{~dB}$, Rt $120 \mathrm{~dB}$ & $\mathrm{~F}$ & $7 ; 8$ \\
\hline 15 & $\mathrm{~F}$ & $8 ; 9$ & $4 ; 3$ & Rt & Deaf & $\mathrm{F}$ & $8 ; 6$ \\
\hline 16 & $\mathrm{~F}$ & $7 ; 1$ & $4 ; 5$ & Lt & Lt 90 dB, Rt 100 dB & $\mathrm{F}$ & $7 ; 7$ \\
\hline 17 & M & $8 ; 0$ & $4 ; 2$ & Rt & Lt $80 \mathrm{~dB}$, Rt $80 \mathrm{~dB}$ & M & $8 ; 5$ \\
\hline 18 & M & $7 ; 9$ & $4 ; 8$ & Rt & Lt 100 dB, Rt $100 \mathrm{~dB}$ & M & $8 ; 3$ \\
\hline 19 & $\mathrm{~F}$ & $7 ; 2$ & $4 ; 5$ & Rt & Lt 90 dB, Rt 90 dB & $\mathrm{F}$ & $7 ; 5$ \\
\hline 20 & $\mathrm{~F}$ & $6 ; 5$ & $4 ; 3$ & Rt & Lt 100 dB, Rt 90 dB & $\mathrm{F}$ & $6 ; 7$ \\
\hline
\end{tabular}

CI: cochlear implants, CI-A: after 3 years old, CI-B: before 3 years old, NH: normal hearing

Table 2. Classification of abnormal nasalance score group*

\begin{tabular}{ll}
\hline Resonance type & $\begin{array}{l}\text { Nasalance score criteria of speech passage task } \\
( \pm 2 \text { SD })\end{array}$ \\
\hline $\begin{array}{l}\text { Hypernasality } \\
\text { Hyponasality }\end{array}$ & $\begin{array}{l}\text { Nasalance score of oral sound passage } \geq 20.36 \% \\
\text { Mixed nasality }\end{array}$ \\
& Nasalance score of nasal sound passage $\leq 50.68 \%$ \\
& Nasalance score of nasal sound passage $\leq 50.68 \%$ \\
\hline
\end{tabular}

*Kim(2009). SD: standard deviation

\section{검사의 실시 절차 및 방법}

$\mathrm{CI}$ 아동은 대구, 부산의 청각학교와 사설 언어치료실에서 언 어 치료를 받고 있는 만 5 8세 아동이며, 자료 수집은 학교와 대상자의 집에서 수집하였다. 자료 수집 시 외부와 소음이 통 제된 곳에서 진행하였다. 건청 아동은 어린이집, 유치원, 초등학 교의 외부와 소음이 통제된 곳에서 진행하였다. 대상자들이 실 험기기와 실험 과정에 대한 심리적인 긴장감을 없애기 위해서 미리 라포르를 형성한 뒤, 검사 실시 과정에 간단히 구두 설명을 한 후에 본 실험에 앞서 2회 미리 연습을 한 뒤 시작하였으며, 음성의 녹음은 소음이 통제된 곳에서 실시하였다.

비음치를 평가하기 위하여 Nasometer II 6564 (KAY Elemetrics Corp., Lincoln Park, NJ, USA)를 사용하였다. 비음 측
정기(Nasometer)의 설치는 반향파의 방해를 방지하기 위해서 먼저 캘리브레이션을 실시하였다. 이때 기기는 벽으로부터 91 $\mathrm{cm}$, 본체의 스피커와 헤드셋은 $30 \mathrm{~cm}$ 정도의 거리를 두었다. Bar mode에서 비음도 막대 그래프가 50\% 선이 되도록 캘리브 레이션 보정을 하였으며, Nasometer의 헤드셋을 대상자에게 씨 운 후 코와 입술 사이의 판은 입술의 움직임을 방해하거나 코 를 막지 않은 위치에 놓고 $90^{\circ} \pm 15^{\circ}$ 로 고정시켜 편안하고 자연 스럽게 말하도록 하였다. 대상자가 문장을 말하지 못하면 한 낱말 씩 끊어서 따라하도록 하였다. 음성 자료 수집 시 $\mathrm{KP}-\mathrm{PRO} 32 \mathrm{~GB}$ (idamtech, Seoul, Korea)로 24 bit $48 \mathrm{kHz}$ wave 디지털 녹음기 를 사용했다. 편안히 앉은 자세에서 입과 녹음기의 거리가 10 $\mathrm{cm}$ 되도록 조절하였다. 대상자들에게 /아/, /이//, /우/ 모음을 3 초 동안 연장 발성, /아, 이, 우/ 연속발성, 구강음 문단, 비음 문 단, 구강음-비음 문단을 녹음하였다.

\section{자료 분석 및 통계 처리}

비음치를 분석하기 위해서 모음 연장 발성의 경우 대상자들 이 3번 발화한 것 중에서 가장 안정적인 발화를 선택하여 비음 치를 측정하였다. 청지각적 평가는 연구자와 음성 치료 경험이 10 년 이상인 1 급 언어치료사가 2 명이 무작위로 배열된 대상자 
들의 검사어를 듣고 평정하였으며, 평정자 $1,2,3$ 인의 일치도는 Kappa 분석을 통해 이루어졌으며, 공명의 수직적 위치 평정의 평정자 간 일치도는 각각 두개강 0.73 , 비강 0.86 , 인두강 0.65 였 다. 공명의 수직적 위치를 두개강, 비강, 인두강으로 분류하였다.

$\mathrm{CI}$ 아동과 건청 아동의 과제별 비음치 비교 $\mathrm{CI}$ 시기에 따른 비음치를 통계분석하기 위해 SPSS version 20.0 (IBM Corp., Armonk, NY, USA) 소프트웨어를 이용하였다. 모음에 대한 $\mathrm{CI}$ 아동과 건청 아동 간의 모음 비음치 비교, 모음의 종류에 따 른 집단 간의 비음치 차이에 대해서는 이원분산분석을 실시하 였으며, 모음에 따른 차이를 보기 위해 Scheffe 사후 검정을 실 시하였다. CI 시기에 따른 모음의 비음치 비교를 위해 평균과 표준편차를 구하였고, 이식 시기와 모음의 종류에 따른 비음치 차이를 구하기 위해 이원분산분석을 하였다. CI 아동과 건청 아 동 간의 문단 읽기 과제별 비음치 비교 및 CI 시기에 따른 비음 치 비교를 위하여 독립표본 t-검정을 실시하였다.

\section{RESULTS}

\section{$\mathrm{Cl}$ 아동과 건청 아동의 모음 비음치 비교}

$\mathrm{CI}$ 아동과 건청 아동의 모음별 비음치 평균에서 건청 아동 의 모음 / 아/는 7.2, / 이/는 15.0, /우/는 7.9로 비음치는 모음 / 이/ $>/$ 우/ > / 아/ 순으로 나타났다. 한편, CI 아동의 모음 /아/는 $14.5, /$ 이/는 21.7, /우/는 14.7로 건청 아동의 모음의 비음치보다 모두 높게 나타났으며, 건청 아동과 마찬가지로 모음 /이/ > /우/ $>/$ 아/ 순으로 /이/의 비음치가 가장 높게 나타났으며, /아/의

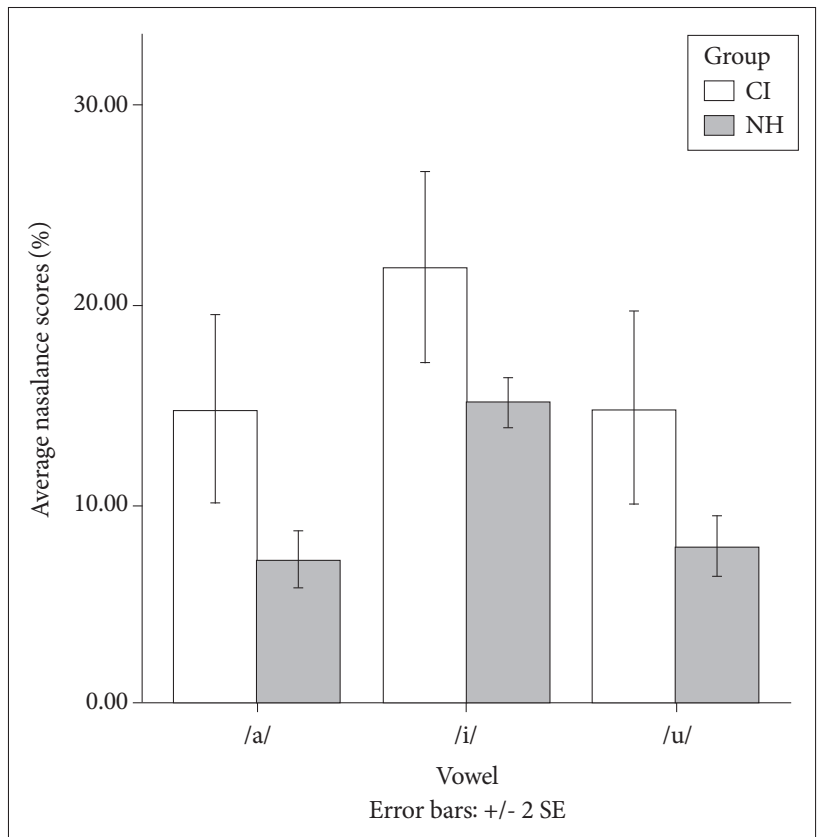

Figure 1. Comparison of nasalance scores of vowel produced by $\mathrm{Cl}$ and $\mathrm{NH}$ children. $\mathrm{Cl}$ : cochlear implants, $\mathrm{NH}$ : normal hearing.
비음치가 가장 낮았다(Figure 1). 모음 /아, 이, 우/의 종류에 따 른 건청 아동과 CI 아동 집단의 비음치의 차이에 대한 분산분석 결과, 집단 간 비음치가 통계적으로 유의한 차이를 보였고 $\left[\mathrm{F}_{(1,114)}\right.$ $=23.574, p=0.000]$, 모음에 따른 비음치도 유의한 차이를 보였 다 $\left[\mathrm{F}_{(2,114)}=11.259, p=0.000\right]$. 즉, $\mathrm{CI}$ 아동 집단이 건청 아동 집 단에 비해 통계적으로 유의하게 높은 비음치를 나타내었다. 모 음에 따른 차이를 보기 위해 Scheffe 사후 검정 결과, 모음 /이/ 와 모음 $/$ 아/ $(p=0.000)$, 모음 $/$ 이/와 모음 $/$ 우/ $(p=0.001)$ 간에 유의한 차이를 보였다. 집단과 모음 간의 교호작용은 통계적으 로 유의하지 않았다 $\left[\mathrm{F}_{(2,14)}=0.025, p=0.975\right]$ (Table 3).

\section{$\mathrm{Cl}$ 아동의 이식 시기에 따른 모음 비음치 비교}

$\mathrm{CI}$ 아동의 이식 시기에 따른 모음 /아, 이, 우/에 대한 비음치 를 분석한 결과, 3 세 이전 이식 아동의 모음 /아/는 13.4, /이/는 24.4, /우/는 13.3으로 나타났으며, 3세 이후 이식 아동의 모음 / 아/는 15.9, /이/는 19.0, /우/는 16.1로 나타났다. CI 아동의 이 식 시기와 모음의 종류에 따른 비음치 차이에 대한 분산분석 결 과, 이식 시기에 따른 두 집단 간 비음치는 통계적으로 유의한 차 이를 보이지 않았으며 $\left[\mathrm{F}_{(1,54)}=0.000, p=0.991\right]$, 모음에 따라서도 유의한 차이를 보이지 않았다 $\left[\mathrm{F}_{(2,54)}=2.806, p=0.069\right]$. 즉, 3 세 이전 CI 아동 집단이 3세 이후 CI 아동 집단에 비해 모음 /아/ 와 /우/에서는 낮은 비음치를 보였고, 모음 / 이/에서는 높은 비음 치를 보였으나 통계적으로 유의하지는 않았다. 집단과 모음 간 의 교호작용은 통계적으로 유의하지 않았다 $\left[\mathrm{F}_{(2,54)}=0.922, p=\right.$

Table 3. Comparison of nasalance scores in $\mathrm{Cl}$ children and $\mathrm{NH}$ children according to vowel types

\begin{tabular}{clrccc}
\hline Vowel & Group & \multicolumn{1}{c}{$\mathrm{M}$} & \multicolumn{1}{c}{ SD } & $\mathrm{F}$ & $p$ \\
\hline /a/ & $\mathrm{CI}(\mathrm{n}=20)$ & 14.5 & 10.5 & 11.259 & $0.000^{*}$ \\
& $\mathrm{NH}(\mathrm{n}=20)$ & 7.2 & 3.24 & & \\
$/ \mathrm{i} /$ & $\mathrm{CI}(\mathrm{n}=20)$ & 21.7 & 10.8 & & \\
& $\mathrm{NH}(\mathrm{n}=20)$ & 15.0 & 2.75 & & \\
$/ \mathrm{u} /$ & $\mathrm{CI}(\mathrm{n}=20)$ & 14.7 & 10.9 & & \\
& $\mathrm{NH}(\mathrm{n}=20)$ & 7.9 & 3.4 & & \\
\hline
\end{tabular}

${ }^{*} p<0.05$. CI: cochlear implants, NH: normal hearing, M: mean, SD: standard deviation

Table 4. Comparison of nasalance scores in $\mathrm{Cl}$ and $\mathrm{NH}$ children according to $\mathrm{Cl}$ period

\begin{tabular}{cccccc}
\hline Vowel & Group & M & SD & F & $p$ \\
\hline /a/ & CI-B $(\mathrm{n}=10)$ & 13.4 & 8.40 & 0.000 & 0.991 \\
& CI-A $(\mathrm{n}=10)$ & 15.9 & 12.70 & & \\
$/ \mathrm{i} /$ & CI-B $(\mathrm{n}=20)$ & 24.4 & 8.70 & & \\
& CI-A $(\mathrm{n}=10)$ & 19.0 & 12.3 & & \\
$/ \mathrm{u} /$ & CI-B $(\mathrm{n}=20)$ & 13.3 & 8.60 & & \\
& CI-A $(\mathrm{n}=10)$ & 16.1 & 13.1 & & \\
\hline
\end{tabular}

${ }^{*} p<0.05$. CI: cochlear implants, CI-A: after 3 years old, CI-B: before 3 years old, $\mathrm{NH}$ : normal hearing, $\mathrm{M}$ : mean, SD: standard deviation 
0.404] (Table 4).

\section{$\mathrm{Cl}$ 아동과 건청 아동, $\mathrm{Cl}$ 아동의 $\mathrm{Cl}$ 시기에 따른 구강음 문단의 비음치}

$\mathrm{CI}$ 아동과 건청 아동의 구강음 문단의 비음치를 비교한 결 과, 건청 아동의 비음치는 $15.8, \mathrm{CI}$ 아동의 구강음 문단의 비음치 는 24.2로 나타났으며, 두 집단 간에 통계적으로 유의한 차이가 있었다 $(\mathrm{t}=-2.545, p=0.015)$. 즉, $\mathrm{CI}$ 아동의 구강음 비음치가 건 청 아동에 비해 유의하게 높았다(Figure 2).

$\mathrm{CI}$ 아동의 $\mathrm{CI}$ 시기에 따른 구강음 문단의 비음치를 비교했 을 때, 3 세 이전 $\mathrm{CI}$ 아동과 3 세 이후 $\mathrm{CI}$ 아동의 구강음 문단의 비음치 평균은 3세 이전 아동의 구강음 문단의 비음치는 24.4, 3 세 이후 CI 아동의 구강음 문단의 비음치는 23.9로 나타났으 며, 두 집단 간에 통계적으로 유의한 차이는 없었다 $(\mathrm{t}=0.079$, $p=0.938)$.

\section{$\mathrm{Cl}$ 아동과 건청 아동, $\mathrm{Cl}$ 아동의 $\mathrm{Cl}$ 시기에 따른 비음 문단의 비음치 비교}

$\mathrm{CI}$ 아동과 건청 아동의 비음 문단에 대한 비음치를 비교한 결과, 건청 아동의 비음치는 $55.0, \mathrm{CI}$ 아동의 비음 문단의 비음 치는 52.4로 나타났으며, 건청 아동 집단의 비음 문단의 비음치 가 높았으나 통계적으로 유의한 차이가 없었다 $(\mathrm{t}=1.200, p=$ 0.237).

$\mathrm{CI}$ 아동의 $\mathrm{CI}$ 아동 시기에 따른 비음 문단의 비음치를 비교 했을 때, 3세 이전 아동의 비음 문단의 비음치는 48.9, 3세 이후 $\mathrm{CI}$ 아동의 비음 문단의 비음치는 55.9로 나타났으며, 두 집단 간에 통계적으로 유의한 차이는 없었다 $(\mathrm{t}=1.600, p=0.127)$ (Figure 3).

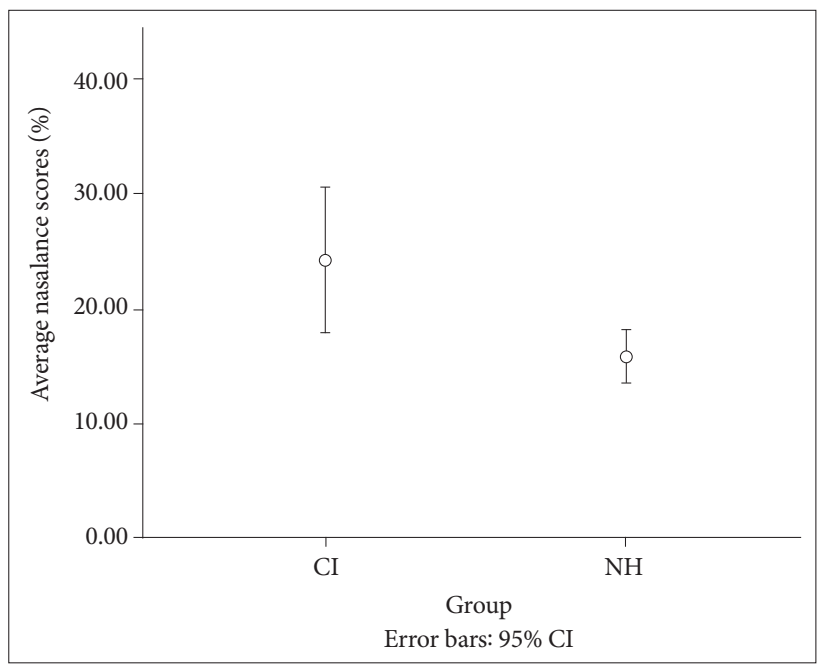

Figure 2. Comparison of nasalance scores of oral consonant passage between $\mathrm{Cl}$ and $\mathrm{NH}$ children. $\mathrm{Cl}$ : cochlear implants, $\mathrm{NH}$ : normal hearing.

\section{$\mathrm{Cl}$ 아동과 건청 아동, $\mathrm{Cl}$ 아동의 $\mathrm{Cl}$ 시기에 따른 구강음-비음 문단의 비음치}

CI 아동과 건청 아동의 구강음-비음 문단에 대한 비음치를 비교한 결과, 건청 아동의 비음치는 $32.9, \mathrm{CI}$ 아동의 구강음-비 음 문단의 비음치는 30.4 로 나타났으며, 두 집단의 유의한 차이 는 없었다 $(\mathrm{t}=-0.681, p=0.500)$

$\mathrm{CI}$ 아동 중 $\mathrm{CI}$ 시기에 따른 구강음-비음 문단의 비음치는 3 세 이전 아동의 구강음-비음 문단의 비음치는 $33.7,3$ 세 이후 $\mathrm{CI}$ 아동의 구강음-비음 문단의 비음치는 32.0으로 나타났으며, 두 집단 간에 통계적으로 유의한 차이는 없었다 $(\mathrm{t}=0.231, p=$ 0.820).

\section{$\mathrm{Cl}$ 아동의 이식 시기에 따른 청지각적 평가}

3 세 이전에 이식을 받은 $\mathrm{CI}$ 아동 10 명 중 정상적인 공명을 나 타내는 아동은 1명, 3 세 이후에 이식을 받은 CI 아동 10 명 중에 서는 2 명으로 이식 시기와 관련 없이 정상 공명을 나타내는 경 우는 총 20명 중 2 명으로 매우 드물었다.

3 세 이전 CI 아동군에서는 과다비성은 4/10명(40\%), 과소비성 은 3/10명(30\%), 혼합비성은 2/10명(20\%) 순으로 나타났으며, 3 세 이후 $\mathrm{CI}$ 아동군에서는 과다비성 5/10(50\%), 과소비성 2/10 (20\%), 맹관공명 $1 / 10(10 \%)$ 순으로 CI 아동의 공명 장애의 형 태는 과다비성이 가장 많았다.

3 세 이전에 이식을 받은 $\mathrm{CI}$ 아동 10 명의 공명 위치는 구강 0/10명(0\%), 두개강 $1 / 10$ 명(20\%), 비강 5/10명(50\%), 인두강 $3 / 10$ 명(30\%)으로 비강이 가장 많았다. 3세 이후 $\mathrm{CI}$ 를 받은 아동 10 명의 공명 위치는 구강 $1 / 10$ 명(10\%), 두개강 $1 / 10$ 명(10\%), 비강 $6 / 10$ 명(60\%), 인두강 2/10명(20\%)으로 비강이 가장 많았으며, 구강공명도 1 명 있었으나 대부분 공명의 위치가 구강이 아닌 비

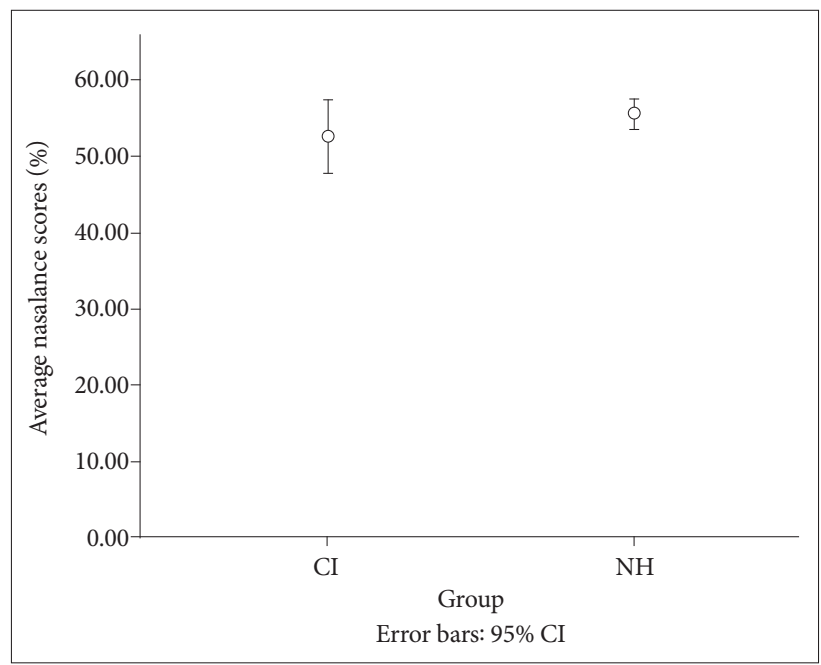

Figure 3. Comparison of nasalance scores of nasal consonant passage between $\mathrm{Cl}$ and $\mathrm{NH}$ children. $\mathrm{Cl}$ : cochlear implants, $\mathrm{NH}$ : normal hearing. 
강이나 인두강 혹은 두개강에 위치하였다.

$\mathrm{CI}$ 시기에 따른 음성 음질의 경우, 3세 이전에 CI 아동에서 정상 음질은 6/10명(60\%)으로 가장 많았으나, 쉰 목소리 2/10 명(20\%), 긴장되고 쥐어짜는 듯한 음질 $2 / 10$ 명(20\%)을 보였다. 한편, 3세 이후 CI 아동의 경우는 정상 음질 3/10명(30\%), 쉰 목 소리 5/10명(50\%), 긴장되고 쥐어짜는 소리 2/10명(20\%)으로 정 상 음질보다는 쉰 목소리나 긴장되고 쥐어짜는 듯한 장애 음성 의 음질을 보였다(Table 5).

\section{DISCUSSIONS}

본 연구는 CI 아동의 공명 특성을 알아보기 위하여 발화 과 제와 이식 시기에 따른 CI 아동의 음성 음향학적, 청지각적 특 성을 조사하였다.

\section{$\mathrm{Cl}$ 아동과 건청 아동의 모음 비음치 비교}

$\mathrm{CI}$ 아동과 건청 아동 간 모음 /아, 이, 우/의 비음치 평균에서 건청 아동의 모음 비음치는 / 이/ > / 우/ > / 아/ 순으로 나타났 다. 또한 CI 아동의 모음의 비음치는 건청 아동보다 모두 높게

Table 5. Auditorty-perceptual characteristics of resonance based on $\mathrm{Cl}$ surgery period

\begin{tabular}{cclll}
\hline Period & $\begin{array}{c}\text { CI period } \\
\text { (year;month) }\end{array}$ & $\begin{array}{c}\text { Type of resonance } \\
\text { disorders }\end{array}$ & $\begin{array}{l}\text { Resonance } \\
\text { place }\end{array}$ & $\begin{array}{c}\text { Voice } \\
\text { quality }\end{array}$ \\
\hline CI-B & & & & \\
1 & $2 ; 00$ & Hyponasality & Cranial & Normal \\
2 & $2 ; 00$ & Hypernasality & Nasal & Normal \\
3 & $2 ; 00$ & Mixed & Pharyngeal & Normal \\
4 & $2 ; 00$ & Mixed & Cranial & Hoarse \\
5 & $2 ; 6$ & Hypo & Nasal & Normal \\
6 & $1 ; 6$ & Hypo & Nasal & Strained \\
7 & $2 ; 0$ & Normal & Pharyngeal & Strained \\
8 & $2 ; 0$ & Hyper & Pharyngeal & Normal \\
9 & $2 ; 0$ & Hyper & Nasal & Hoarse \\
10 & $1 ; 8$ & Hyper & Nasal & Normal \\
CI-A & & & & \\
1 & $3 ; 4$ & Normal & Nasal & Hoarse \\
2 & $3 ; 0$ & Hypo & Nasal & Horase \\
3 & $3 ; 3$ & Hyper & Pharyngeal & Strained \\
4 & $3 ; 11$ & Hypo & Nasal & Hoarse \\
5 & $4 ; 3$ & Hyper & Cranial & Hoarse \\
6 & $4 ; 5$ & Hyper & Nasal & Strained \\
7 & $4 ; 2$ & Hyper & Nasal & Normal \\
8 & $4 ; 8$ & Cul-de-sac & Pharyngeal & Normal \\
9 & $4 ; 5$ & Normal & Oral & Horase \\
10 & $4 ; 3$ & Hyper & Nasal & Normal \\
\hline CI: & & & & \\
\hline
\end{tabular}

CI: cochlear implants, CI-A: after 3 years old, CI-B: before 3 years old, Hyper: hypernasality, hypo: hyponasality, Mixed: mixed nasality
나타났으며, 건청 아동과 마찬가지로 모음 /이/ > /우/ > / 아/ 순으로 /이/의 비음치가 가장 높게 나타났으며, /아/의 비음치가 가장 낮았다. 모음 / 아, 이, 우/의 종류에 따른 건청 아동과 CI 아동 집단의 비음치의 차이에 대한 이원분산분석 결과 집단 간 비음치가 통계적으로 유의한 차이를 보였고, 모음에 따라 유의 한 차이를 보였다. 즉, $\mathrm{CI}$ 집단이 건청 아동 집단에 비해 통계적 으로 유의하게 높은 비음치를 나타내었다. 모음에 따른 차이를 보기 위해 Scheffe 사후 검정 결과, 모음 /이/와 /아/, 모음 /이/ 와 /우/ 간에 유의한 차이를 보였다. 집단과 모음 간의 교호작 용은 통계적으로 유의하지 않았다. Choi et al.(2010)의 연구에 서는 CI 아동이 보청기 착용 아동보다 높은 비음치를 보여 CI 아동의 청력 수준의 향상과 비음도와 상관관계가 없었다. 본 연구의 결과에서도 CI 아동이 건청 아동에 비해 모음의 비음치 가 유의하게 높았다. 이러한 결과는 청력 수준이 개선되었음에 도 선천성 난청과 고심도 난청으로 인해 이식 이전에 듣지 못했 던 소리에 대한 청각적 피드백의 부재가 이식 후에도 여전히 일 탈된 공명 문제를 나타내는 것으로 보인다. 또한 모음 중 고모 음 /이/의 비음치가 가장 유의하게 높게 나타났는데, 혀의 위치 가 상대적으로 구강 안에서 전상방으로 이동함으로써 후두로부 터 올라오는 기류의 에너지가 비강 쪽으로 이동함으로써 상대적 으로 다른 후설 저모음/아/나 후설 고모음/우/에 비해 높은 비 음치를 산출한 것으로 보인다.

\section{$\mathrm{Cl}$ 아동의 이식 시기에 따른 모음 비음치 비교}

$\mathrm{CI}$ 아동의 이식 시기와 모음의 종류에 따른 비음치 차이에 대한 이원분산분석 결과, 이식 시기에 따른 두 집단 간 비음치 는 통계적으로 유의한 차이를 보이지 않았으며, 모음에 따라서 도 유의한 차이를 보이지 않았다. 3세 이전 CI 아동 집단이 3세 이후 CI 아동 집단에 비해 모음 / 아/와 /우/에서는 낮은 비음치 를 보였고, 모음 /이/에서는 높은 비음치를 보였으나 통계적으 로 유의하지는 않았다. 집단과 모음 간의 교호작용은 통계적으 로 유의하지 않았다. 이러한 특성은 비음치가 CI 연령과는 상 관이 없음을 보여준다. 즉, $\mathrm{CI}$ 를 일찍 받았더라도 여전히 높은 비음치를 보여 비정상적인 공명 특성을 나타내었다.

\section{$\mathrm{Cl}$ 아동과 건청 아동의 문단 읽기 비음치 비교}

$\mathrm{CI}$ 아동과 건청 아동 간의 문단 읽기 과제에서 첫째, 구강음 비음치 비교에서 건청 아동과 $\mathrm{CI}$ 아동의 두 집단 간에 통계적 으로 유의한 차이가 있었다. 즉 CI 아동의 구강음 비음치가 건 청 아동에 비해 유의하게 높았다. 그리고 CI 시기에 따른 3세 이전과 3세 이후 $\mathrm{CI}$ 아동의 구강음 문단의 비음치는 통계적으 로 유의한 차이가 없었다. 높은 구강음 문단의 비음치는 과다 비성으로 분류할 수 있으며, CI 연령에 상관없이 여전히 높은 
비음치를 보이는 과다비성의 공명 형태를 보였다. 즉, 구강음 문 단에서 건청 아동에 비해 CI 아동이 연인두를 덜 폐쇄함으로 써 기류가 비강쪽으로 이동하는 형태를 보였다. 둘째, CI 아동 과 건청 아동의 비음 문단의 비음치에서 건청 아동의 비음 문 단의 비음치가 높았으나 통계적으로 유의한 차이가 없었다. 즉, 비음 문단에서 CI 아동은 통계적으로 유의하지는 않았으나, 건 청 아동에 비해 구강음 문단과는 반대로 비음 산출 시에는 연 인두를 덜 열어 비강에서의 공명이 감소하는 형태를 나타내었 다. 또한, $\mathrm{CI}$ 시기에 따라 3세 이전 $\mathrm{CI}$ 아동과 3세 이후 $\mathrm{CI}$ 아동 의 비음치는 통계적으로 유의한 차이는 없었다. 셋째, $\mathrm{CI}$ 아동 과 건청 아동의 구강음-비음 문단의 비음치는 통계적으로 유의 한 차이가 없었다. CI 시기에 따른 3세 이전과 3세 이후 CI 아 동의 구강음-비음 문단의 비음치는 통계적으로 유의한 차이가 없었다. 국내의 한 선행연구에서 구강음 문단에서는 건청 아동 에 비해 높은 비음치를 보였으나, 비강 구문과 구강음-비음 혼 합 구문에서는 낮은 비음치를 보였다(Yoon et al., 2013). 이와 마찬가지로 본 연구에서도 $\mathrm{CI}$ 아동이 건청 아동에 비해 구강 음-비음 문단에서 낮은 비음치를 보였으나, 통계적으로 유의한 차이는 보이지 않았다.

본 연구의 결과를 종합해 볼 때, CI 아동들의 비음치는 말 과 제에 따라 상이하게 나타났는데, 구강음 문단에서는 건청 아동 보다 높고, 비음 문단의 비음치는 건청 아동보다 낮게 나타났으 나 통계적으로는 유의한 차이가 없었으며, 구강음-비음 문단의 비음치도 건청 아동보다 낮았으나 유의한 차이는 없었다. 국내 의 선천성 심도 청각 장애 성인의 비음치 연구에서도 구강 자 음 과제에서는 건청군보다 청각 장애군이 높은 비음치를, 비음 과제와 비강-구강 자음 혼합 과제에서는 낮은 비음치를 보여 본 연구와 유사한 패턴을 보였다(Kim, 2009). 본 연구의 이와 같은 결과는, $\mathrm{CI}$ 아동이 구강음 문단 산출 시 비강으로 더 많은 기 류를 산출하며, 비강 문장 산출 시 구강으로 더 많은 기류를 산출한 것으로 보인다. 또한 이러한 현상은 구개열 아동과 같이 기질적인 문제로 인한 연인두 폐쇄부전에 의한 과다비성과 과 소비성의 산출 형태와 다르며, CI 아동은 심도 난청으로 인해 와우 이식 이전에 소리를 들을 수 없어 구강과 비강의 분리가 잘 이루어지지 않으며, 연인두 개폐에 대한 협응 기능을 잘 사 용하지 못하는 것으로 추측된다. 이러한 연인두 기능 조절의 어 려움으로 인해 기질적인 문제가 없음에도 불구하고 연인두 폐 쇄 시 연인두를 덜 닫거나, 연인두 개방 시 덜 여는 양상을 보이 기도 하였다. 이러한 연인두 기능의 비일관적인 사용으로 인해 구강음 산출 시 비강으로 더 많은 기류를 흘려보내 건청 아동 보다 구강음의 비음치가 더 높았으며, 비음 문단 산출 시에도 구강으로 더 많은 기류를 흘려보내 건청 아동보다 더 낮은 비 음치를 산출하였다. 또한, $\mathrm{CI}$ 시기에 따른 3 세 이전과 3 세 이후
$\mathrm{CI}$ 아동의 비음치는 유의한 차이를 보이지 않아, CI 연령과 상 관없이 비정상적인 비음치를 산출하였다. 이러한 결과는 $\mathrm{CI}$ 를 조기에 받아 청력의 개선이 조기에 이루어져서 공명 기관 기능 의 사용이 조기에 이루어짐으로써 공명 기관의 적절한 조절에 대한 학습이 조기에 이루어질 것으로 추측하였으나, 이식 이후 에도 잘못 학습된 오류의 형태를 사용함으로써 3세 이후에도 여전히 공명의 문제를 보이는 아동이 많았다. 따라서 CI 이후 에 조음과 같은 분절적 요소 이외에 정상적인 말소리 산출을 위하여 공명, 음질과 같은 초분절적 요소에 대한 청능 재활 훈 련이 필요하였다.

\section{$\mathrm{Cl}$ 아동의 이식 시기에 따른 공명에 대한 청지각적 평가}

$\mathrm{CI}$ 아동의 이식 시기에 따른 청지각적 평가에서 연구결과 이 식 시기와 관련 없이 정상 공명을 나타내는 경우는 총 20명 중 2 명으로 매우 드물게 나타났으며, 과다비성 > 과소비성 > 혼 합비성 및 맹관공명 순으로 $\mathrm{CI}$ 아동 대부분이 일탈된 공명 장 애를 보였다. 건청 아동은 구강음에서 연인두 밸브를 폐쇄하고 비음 산출 시 연인두 밸브를 개방하지만, 청각 장애 아동은 연 구개 밸브의 개폐 오류를 보였으며, 이러한 연구개 운동의 잘못 학습된 오류로 인해 공명의 문제를 보였다. 또한, 본 연구의 $\mathrm{CI}$ 아동의 구문 읽기 과제에 있어 구강음 문장에서 건청 아동보다 비음치가 더 높은 반면, 통계적으로 유의하지는 않았지만 비음 문단에서 건청 아동보다 낮은 비음치가 나타나 양극단의 형태 를 나타냈다. 이러한 결과는 CI 아동의 CI 이후에도 개선된 청 각적 피드백으로 공명의 문제가 해결되지 못했으며, 이전에 잘 못 학습된 오류가 여전히 남아 있어 구강음에 산출 시 더 많이 비강으로 기류를 산출하고 비음 산출 시 구강으로 더 많은 기 류를 산출하는 형태를 보였다. 또한 구개파열처럼 기질적인 문 제가 없음에도 불구하고 발성 시 기류의 조절을 잘 못하거나 기류의 산출 시 시간이 지연되어 산출되기도 하였다. 또한 $\mathrm{CI}$ 아동의 공명 문제를 평가할 때는 매우 복잡하고 덜 일관적인 형태의 패턴을 나타내어 단순히 구강과 비강의 비율로 공명의 문제를 평가하는 것은 무리가 따를 것으로 보인다. 왜냐하면 청각 장애 아동은 공명 기관을 건청 아동과 다르게 사용하거 나, 공명강 사용 자체에 문제가 있을 수도 있기 때문이다. 본 연 구에서 청각 장애 아동은 단순히 비강과 구강의 공명으로 말소 리를 산출하지 않았으며, 부비동을 울리며 공명을 사용하거나 인두공명을 사용해서 공명을 하는 경우도 있었다. 따라서, 청각 장애 아동의 공명 특성을 평가하기 위해서 기기를 이용한 비음 치 측정치는 객관적인 수치를 제공해 준다는 점에서 유용할 수 있지만 일탈적인 공명이나 말소리 특성을 동반하는 경우 기기 적 측정만으로는 제한점을 갖게 될 수 있다. 이는 공명의 평가 에서 청지각적 평가가 우선 되어야 하며 기기적인 측정치는 공 
명 평가 시 청지각적 평가의 보조 수단으로 병행하여 사용되어 야 할 것이다. 본 연구의 제한점 및 후속연구를 위한 제안은 다 음과 같다.

첫째, 본 연구에서 $\mathrm{CI}$ 아동들의 공명 특성을 파악하기 위하 여 기기적 평가인 비음치와 청지각적 평가를 사용하였는데, 이 러한 평가방법과 함께 객관적인 음성검사를 위한 음향 음성학 적 검사와 공기역학적 검사 및 비인두 내시경과 투시조영검사 와 같은 다양한 검사를 통해 청각 장애 아동의 공명 특성에 대 한 다양한 방법의 접근이 필요하다. 따라서 향후 연구에서는 다양한 형태의 공명 특징과 다양한 검사방법들을 사용한 공명 연구로 확대되어야 할 것이다.

둘째, 본 연구의 과제는 아동의 생활연령으로 인해 제한된 형태의 모음과 문단 읽기 과제를 통한 측정과 평가의 시행이었 다. 따라서 후속연구에서는 비음치에 영향을 주는 다양한 형태 의 말 문맥 과제를 통한 연구가 진행되어야 할 필요가 있다. 셋 째, 본 연구의 대상자 수가 적어서 결과를 일반화시키는 것에 제한이 있으며, CI 아동 간의 이식 시기에 따라서 건청 아동과 의 공명 비교가 이루어졌다. 후속연구에서는 더 많은 대상자를 포함하여 공명 문제를 논의할 필요가 있다. 또한 본 연구의 $\mathrm{CI}$ 아동은 모두 한쪽에만 $\mathrm{CI}$ 를 한 아동으로서 추후에는 양쪽 귀 에 $\mathrm{CI}$ 를 한 아동과 건청 아동의 공명의 특성을 비교해 볼 필요 가 있겠다. 또한 대상자의 청능 훈련 시기와 기간, 인공와우 착 용 기간, 성별 등 다양한 변인을 고려하지 못해, 향후 연구에서 는 이러한 다양한 변인들을 고려한 연구가 진행되어야 할 필요 가 있다.

중심 단어 : 인공와우 · 공명 장애·비음치· 청지각적 평정.

\section{REFERENCES}

Choi, E. A., Park, H. S., \& Seong, C. J. (2010). The phonatory characteristics of voice in profoundly hearing-impaired children: With reference to F0, intensity, and their perturbations. Phonetics and Speech Science, 2(1),
135-145.

Fletcher, S. G. \& Daly, D. A. (1976). Nasalance in utterances of hearing-impaired speakers. Journal of Communication Disorders, 9(1), 63-73.

Fletcher, S. G., Mahfuz, F., \& Hendarmin, H. H. (1999) Nasalance in the speech of children with normal hearing and children with hearing loss. American Journal of Speech-Language Pathology, 8, 241-248.

Jun, E. O. \& Ko, D. H. (2007). The voice quality of the children with cochlear implant according to the time. Korean Journal of Speech Sciences, 14(4), 213-220.

Jung, H. J. (2002). Acoustic comparisons of vowel production between hearing impaired females and normal hearing female (unpublished master's thesis). Hallym University, ChunCheon.

Kim, E. Y. (2009). Evaluation of resonance problems in severe congenital hearing impaired adults: via velopharyngeal function examination. (unpublished doctoral dissertation). Yonsei University, Seoul.

Kim, G. E. \& Ko, D. H. (2007). Acoustic characteristics of some vowels produced by the CI children of various age groups. Korean Journal of Speech Sciences, 14(4), 203-212.

McGarr, N. S. \& Osberger, M. J. (1978). Pitch deviancy and intelligibility of deaf speech. Journal of Communication Disorders, 11(2-3), 237-247.

Mondain, M., Sillon, M., Vieu, A., Lanvin, M., Reuillard-Artieres, F., Tobey, E., et al. (1997). Speech perception skills and speech production intelligibility in French children with prelingual deafness and chochlear implants. Archives Otolaryngology, Head and Neck Surgery, 123(2), 181-184.

Nguyen, L. H., Allegro, J., Low, A., Papsin, B., \& Campisi, P. (2008). Effect of cochlear implantation on nasality in children. Ear, Nose, and Throat Journal, 87(3), 138, 140-143.

Oh, Y. J., Zhi, M. J., \& Kim, Y. T. (2000). Acoustic comparisons of vowel and plosive productions between the normal and the hearing-impaired children. Korean Journal of Speech Sciences, 7, 51-70.

Park, M. K., Lee, E. K., Yu, S., Koh, K. S., Baek, R. M., \& Kim, B. J. (2008). Nasalance Scores in Normal Koreans. Proceedings from 65 th ACPA (American Cleft Palate-Craniofacial Association).

Sehr, K. H., Shim, H., \& Ko, D. H. (2002). Some Characteristics of Formant Frequencies Produced by Hearing Impaired and Normal Adult Males. Journal of Speech-Language and Hearing Disorders, 11(1), 239-254.

Yoon, M. S. (2004). The comparison of fundamental frequencies of children with different hearing level. Malsori, 52, 49-60.

Yoon, M. S., Choi, E. A., \& Sung, Y. (2013). A comparison of voice analysis of children with cochlear implant and with normal hearing. Korean Journal of Speech Sciences, 5(4), 71-78.

Yoon, M. S., Choi, E. I., \& Sung, Y. (2013). The Comparison of Nasalance Scores of Children with Cochlear Implants and Children with Normal Hearing. Journal of Speech-Language and Hearing Disorders, 22(1), 299-310. 
APPENDIX

\section{Speech Materials for Resonance Evaluation}

\begin{tabular}{|c|c|c|c|}
\hline \multicolumn{2}{|c|}{ Speech task } & References* & Content \\
\hline \multirow{3}{*}{\multicolumn{2}{|c|}{ Sustained vowel phonation }} & & la/ \\
\hline & & & /i/ \\
\hline & & & $/ u /$ \\
\hline \multirow[t]{3}{*}{ Reading passages } & $\begin{array}{l}\text { Oral sound passage } \\
\text { (nasal consonant } 0 \% \text { ) }\end{array}$ & $11.94 \%( \pm 4.2)$ & $\begin{array}{l}\text { 수희 가족이 바다에 갔다. 배도 타고 튜브도 탔다. 갑자기 } \\
\text { 비가 와서 집으로 돌아왔다. }\end{array}$ \\
\hline & $\begin{array}{l}\text { Nasal sound passage } \\
\text { (oral consonant } 0 \% \text { ) }\end{array}$ & $63.02 \%( \pm 5.67)$ & $\begin{array}{l}\text { 엄마 안녕, 엄마 안녕, 매미 안녕, 매미 안녕, 나무 안녕, } \\
\text { 나무 안녕 }\end{array}$ \\
\hline & $\begin{array}{l}\text { Oral-nasal passage } \\
\text { (nasal consonant 30\%) }\end{array}$ & $34.73 \%( \pm 4.79)$ & $\begin{array}{l}\text { 오늘은 대공원에 소풍 가는 날이다. 엄마가 김밥도 만드 } \\
\text { 셨다. 과자랑 스케치북도 가져갔다. }\end{array}$ \\
\hline
\end{tabular}

*Park et al.(2008). 